\title{
Extractive Gas-Phase Sampling of the Reaction Zone of a Pressurized
}

\section{Entrained-Flow Coal Gasifier}

\author{
David R. Wagner ${ }^{1}$ and Kevin J. Whitty* \\ Department of Chemical Engineering, The University of Utah, Salt Lake City, Utah 84112 \\ *Telephone: +1-801-585-9388. E-mail: kevin.whitty@utah.edu
}

\begin{abstract}
A novel extractive gas-phase sampling system was developed for use in a pressurized entrainedflow coal gasifier. The system comprised three parts: a water-cooled probe through which the sampled gases travel, a pneumatic cylinder that directs the radial sampling location, and the control system. The system was designed for safe sampling of the harsh environment in gasifiers and can help understand spatial distribution of concentrations in such a system. To confirm operation of the sampling system, gas-phase samples were extracted from the reaction zone of a 1 ton/day pilot entrained-flow coal gasifier operating at a pressure of 11 bar and at temperatures ranging from 1370 to $1540^{\circ} \mathrm{C}$. Concentrations of carbon monoxide and hydrogen decreased with increasing temperature while carbon dioxide increased with temperature, a result of the higher oxygen/fuel ratio needed to achieve the higher temperature. Synthesis gas (syngas) heating values decreased correspondingly with increasing temperature and the heating value of the syngas exiting the gasifier was higher than for syngas extracted from the reaction zone. Under conditions tested, no statistically significant variation in gas composition with radial position was observed.
\end{abstract}

Keywords: Gasification; coal; pressurized; entrained-flow; sampling; gas-phase

\footnotetext{
${ }^{1}$ Present address: Umeå University, Department of Applied Physics and Electronics, Thermochemical Energy Conversion Laboratory, S-90187 Umeå, Sweden
} 


\section{Introduction}

Currently in the United States, coal use produces about 20 quadrillion Btu (0.67 TWyr) of energy per year, which accounts for roughly one-quarter of all energy produced in the country [1]. Efficient use of coal is increasingly important to minimize carbon emissions from power plants and other high temperature processes. By studying the chemical processes in various technologies that produce power and heating from coal, efficiency can be increased. For example, it useful to study gas-phase species distributions within pressurized entrained-flow coal gasifiers to better understand the environment within such systems to improve their design and operation. The high temperatures and pressures at which entrained-flow gasifiers operate, as well as the presence of corrosive and poisonous syngas components and molten slag, make sampling of gases within the reactor very challenging. Previous studies have investigated gas-phase sampling of black liquor [2,3] and dry-fed entrained-flow coal gasification systems focusing on major syngas components [4-6] and sulfur and nitrogen release [7-10]. These studies used probes that were side-mounted to measure gas compositions at specified axial locations. Another method of measuring entrained-flow gasifier gas composition is a bottom-mounted probe fixed at a specified gasifier height. Some laboratory-scale laminar flow [11] and entrained-flow systems [12-15] utilize this bottom-mounted method, but they were unable to quantify radial distributions of synthesis gases.

The objectives of this study were (1) to develop a safe and robust system to sample and measure local gas composition at any radial position between the wall and centerline of a high pressure, slagging entrained-flow gasifier, and (2) to demonstrate the function of this system by sampling gas from a 1 ton/day pressurized entrained-flow gasifier to identify radial distributions of main syngas components within the gasifier. The design of the sampling system, experience 
with its use and example results from an experimental campaign are presented in the sections that follow.

\section{Materials and Methods}

\subsection{Entrained-flow Gasifier}

The pressurized, oxygen-blown, entrained-flow gasifier (EFG) used in this study is located at the University of Utah Industrial Combustion and Gasification Research Facility. The gasifier is $5.22 \mathrm{~m}$ tall, including the reaction and quench zones, and is $0.76 \mathrm{~m}$ in outer diameter. The reaction zone is $0.20 \mathrm{~m}$ in diameter and $1.52 \mathrm{~m}$ in length. A progressive cavity pump delivers coal-water slurry at a rate corresponding to roughly 1 ton/day dry coal to the top of the reactor. High pressure oxygen atomizes the slurry and reacts with the fuel. Figure 1 shows a crosssectional view of the EFG with dimensions and labeled parts of interest. The reactor has several B-type thermocouples located along the length of the reaction zone and positioned flush with the inner wall. In addition to measuring the temperature, the thermocouples provide an indication of reactor performance. These thermocouples are axially aligned with the sample ports. Their tangential position relative to the sampling ports is shown in Figure 2. 


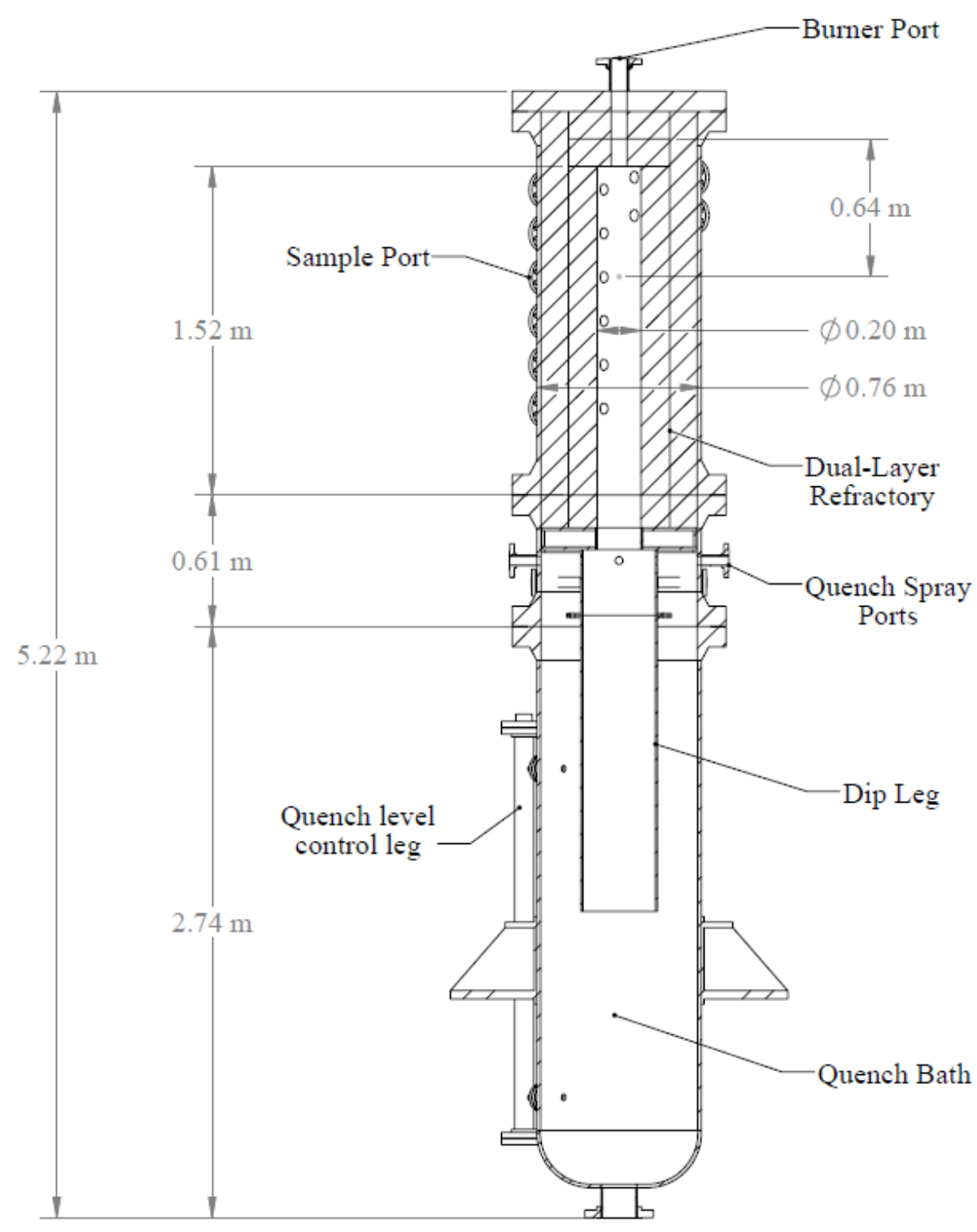

Figure 1: Diagram of the EFG axial cross section. Key parts are labeled, including the port from which synthesis gas was sampled. All dimensions are in meters. 


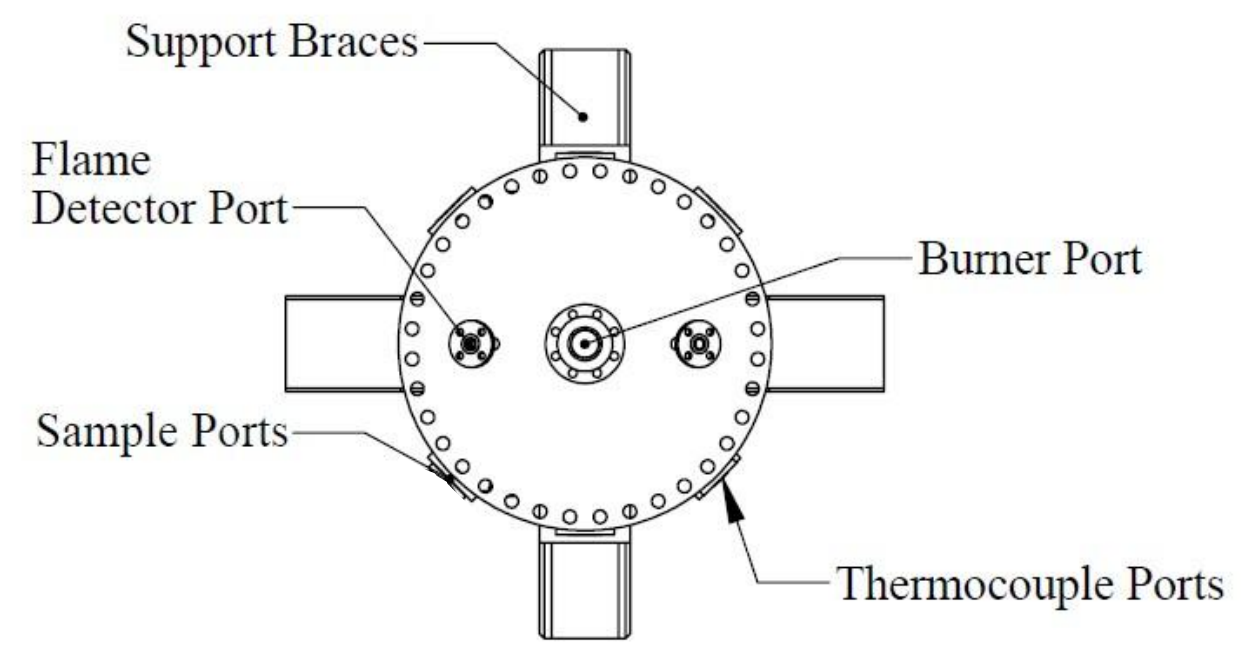

Figure 2: Top view of the EFG. Sample ports and thermocouple ports are labeled in addition to flame detector and burner ports.

\subsection{Sampling System}

The sampling system consisted of three main parts: the probe, the pneumatic position feedback cylinder (PFC) for positioning the probe, and the position control system (PCS). Figure 3 shows a schematic of the system. The pneumatic cylinder (Bimba Manufacturing model PFC7018-L-Y) had a $46 \mathrm{~cm}$ stroke length, allowing the probe to be positioned to within $8 \mathrm{~mm}$ of the full stroke length and repeatable to within $1.3 \mathrm{~mm}$ under pressurized conditions. The control system allowed electronic control of the pneumatic valves routing air to the cylinder. The sampling system and control algorithm are described in detail elsewhere [16], but a brief description is presented here. 


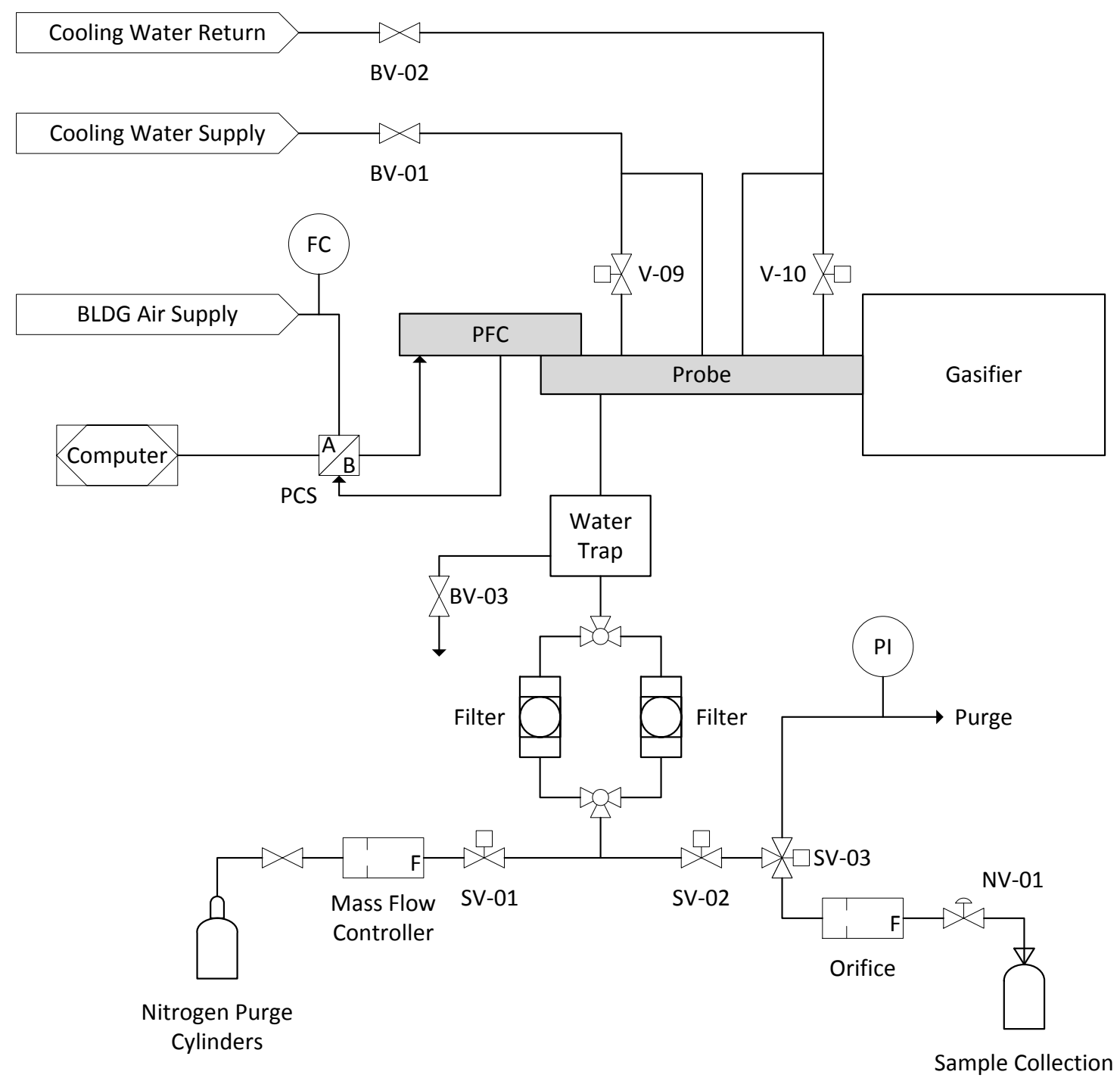

Figure 3: Schematic of the sampling system. BV indicates ball valve, SV indicates solenoid valve, and NV indicates needle valve. FC indicates flow control device and PI represents pressure indicator. PFC is the position feedback cylinder and PCS is the position control system.

The water-cooled sample probe was attached to the positionable pneumatic cylinder at one end and passed through a gasifier-mounted seal/flange assembly at the other end. Figure 4 shows these two sections and the PFC with major components identified, and Figure 5 shows the probe and flange assembly in detail. Not shown in Figure 4 is a U-shaped bracket supporting the $1.6 \mathrm{~kg}$ cylinder and three 16-mm threaded rod pieces extending from the flange assembly 
attached to the gasifier. A tripod supported the far end of the PFC to eliminate strain on the brace.

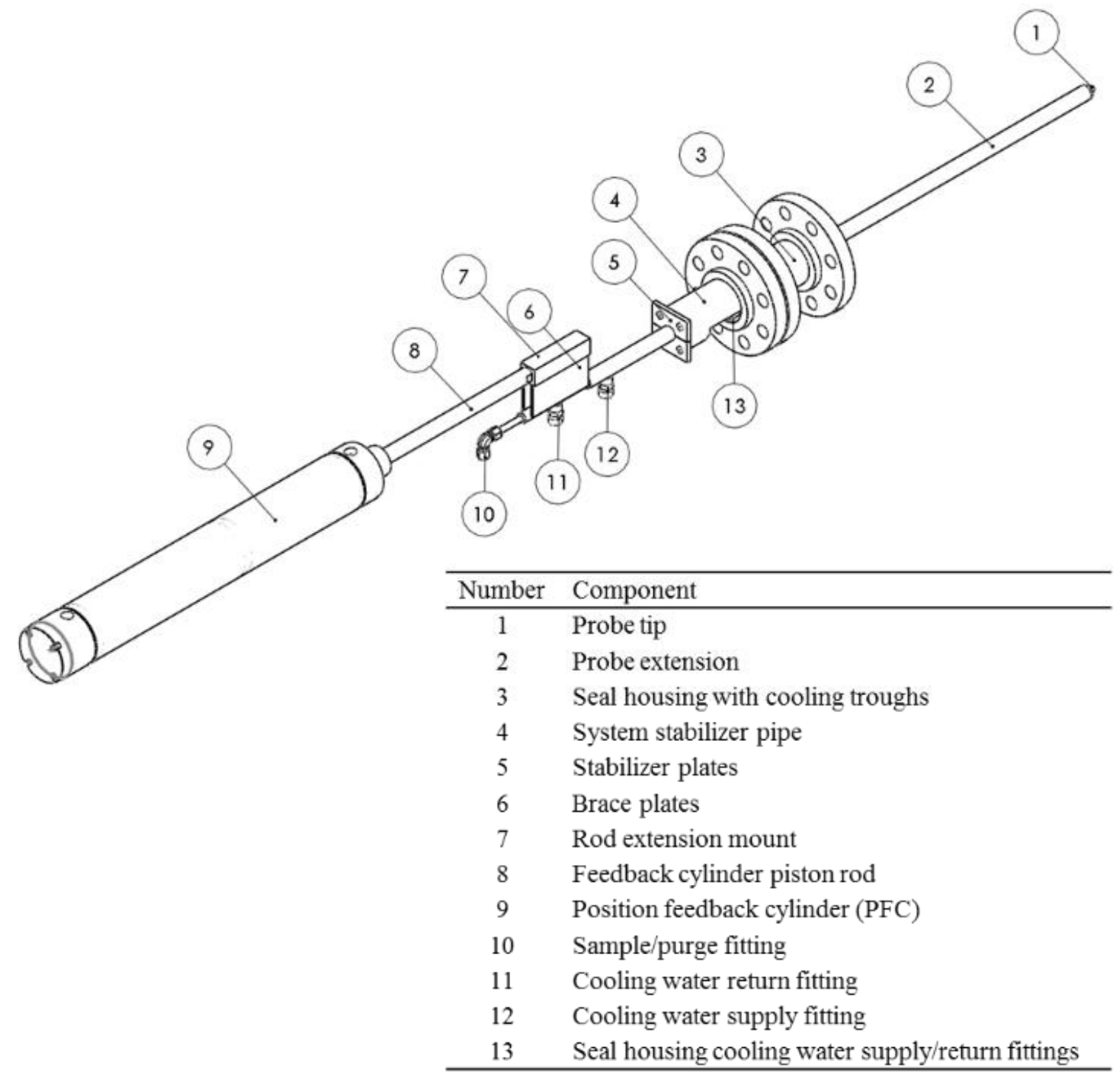

Figure 4: Isometric view of the sample probe (probe and flange assembly) with components identified.

The probe was made of 316 stainless steel tubing, plates, and fittings. It attached to the threaded piston of the cylinder and the threaded rod extension mount of the probe. The sampled gases traveled through a $3 \mathrm{~mm}$ hole on the underside of the probe tip, driven by the pressure 
difference between the reaction zone and sample train. The water-cooled seal housing was machined from 304L stainless steel and the stabilizer pipe and plates were 316 stainless steel. American High Pressure Seals fabricated the high pressure Teflon-based seal. Probe assembly cooling water was supplied by an on-site closed cooling water circuit employing a cooling tower, which serves all EFG subsystems. The cooling water flow rate was limited by available water pressure and probe design to 15 liters per minute.

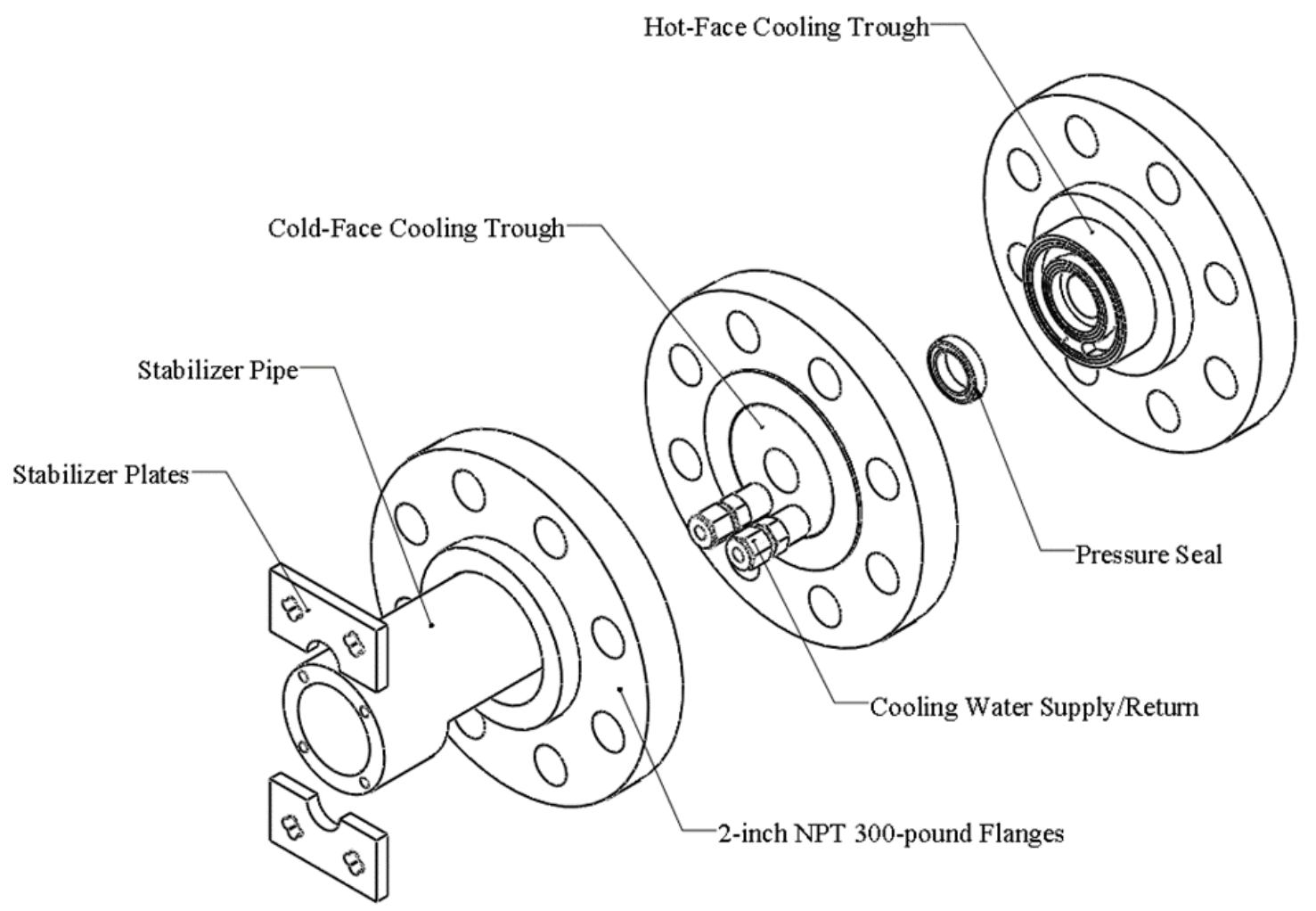

Figure 5: Exploded isometric view of the flange assembly with components identified. Cooling trough gasket-rings not shown for simplicity.

The OPTO 22-based distributed control system (DCS) controlled individual sampling sequences. When sampling was not taking place, nitrogen flowed through the system and into the gasifier to avoid damage to the equipment. To prepare for acquisition of a gas sample, the operator placed a tedlar bag at the exit of needle valve NV-01 in Figure 3 and initiated the 
sampling algorithm in the control software. Independent of the operator, the algorithm simultaneously closed solenoid valve SV-01 and opened solenoid valve SV-02. This allowed reaction zone syngas to begin filling the sample system and purge syngas from three-way solenoid valve SV-03, as indicated in Figure 3. When valves SV-01 and SV-02 switched, the PCS pneumatically positioned the PFC to the setpoint location within the gasifier. After approximately 15 seconds, valve SV-03 switched position and began sampling fresh reaction zone syngas. Depending on gasifier pressure, the sampling took 10 to 20 seconds based on the mass flow rate through the critical orifice between SV-03 and NV-01. After the sampling time passed, the PFC retracted from the gasifier to its original and safe position in the refractory wall of the gasifier and solenoid valves SV-01 and SV-02 switched again, allowing nitrogen to purge the system of remaining syngas. During operation, the dual filter system and water trap caught any particulates greater than 15 micron. Ball valve BV-03 released the condensate from the water trap after the gasifier pressure was lowered to ambient at the end of the day. A Varian micro gas chromatograph, model 4900, later analyzed all gas samples. Wagner [16] presents additional details of individual systems and functionality.

\subsection{Sampling Campaign}

For the sampling campaign, a 56.5 wt-\% coal-water slurry of a Utah bituminous coal, detailed in Table 1, was prepared by mixing pulverized coal (70\% through 200 mesh, approx. 75 micron average particle size) with water and roughly $1 \%$ wt- $\%$ calcium carbonate. Carbon, hydrogen, and nitrogen contents of the coal were determined by ASTM method D5373 and sulfur and oxygen were determined by ASTM methods D4239 and D5622, respectively. Oxygen and hydrogen contents include contributions from sample moisture. A two-stream injector atomized the pumped slurry and oxygen flows at the top of the gasifier. Experience with the gasifier and 
probe as well as safety considerations of the sampling system's pressure seal and flange assembly dictated the operating conditions of the gasifier. A pressure of 11 bar absolute was chosen and three temperatures in the sampling probe location, $1370^{\circ} \mathrm{C}\left(2500^{\circ} \mathrm{F}\right), 1455^{\circ} \mathrm{C}\left(2650^{\circ} \mathrm{F}\right)$, and $1540^{\circ} \mathrm{C}\left(2800^{\circ} \mathrm{F}\right)$, were targeted. Gasifier temperature was adjusted by varying the flow rate of coal-water slurry for a prescribed flow of oxygen. Gas samples were acquired at three radial locations at each of the three temperatures, yielding nine sample conditions. These locations were the wall (W), halfway between the wall and the centerline $(\mathrm{H})$, and the centerline $(\mathrm{C})$, corresponding to distances of 0,5 , and $10 \mathrm{~cm}$ from the reactor wall, respectively. Duplicates obtained for each position, with an extra sample taken at one of these, provided a total of 19 samples $(2 \times 9+1)$. The axial sampling point was located $75 \mathrm{~cm}$ downstream of the injector tip.

Table 1: Ultimate and proximate fuel analyses.

\begin{tabular}{ccccc|cccc}
\hline \multicolumn{4}{c|}{ Ultimate, \% } & ash-free, incl. moisture & \multicolumn{4}{c}{ Proximate, \% as received } \\
\hline C & H & N & O & S & Moisture & Ash & VM & FC \\
\hline 67.87 & 5.45 & 1.09 & 16.87 & 0.36 & 6.11 & 8.36 & 38.49 & 47.04 \\
\hline
\end{tabular}

\section{Results and Discussion}

\subsection{Syngas Concentration}

Measured concentrations of carbon monoxide, hydrogen, and carbon dioxide across all three radial locations are presented versus reactor temperature in Figure 6. Standard error is shown per setpoint temperature and gas species. Variation in measured temperature resulted from dynamic changes as operating conditions were adjusted to achieve the target temperature while maintaining overall system pressure. Samples taken at the middle temperature $\left(1455^{\circ} \mathrm{C}\right)$ and higher temperature $\left(1540^{\circ} \mathrm{C}\right)$ revealed more scatter in the gas concentrations than the lowest temperature $\left(1370^{\circ} \mathrm{C}\right)$ as a result of changes in slurry flow rate to achieve higher temperatures 
and the corresponding lower amount of time available to achieve steady state operation of the gasifier compared to the lower temperature, which was the initial temperature used.
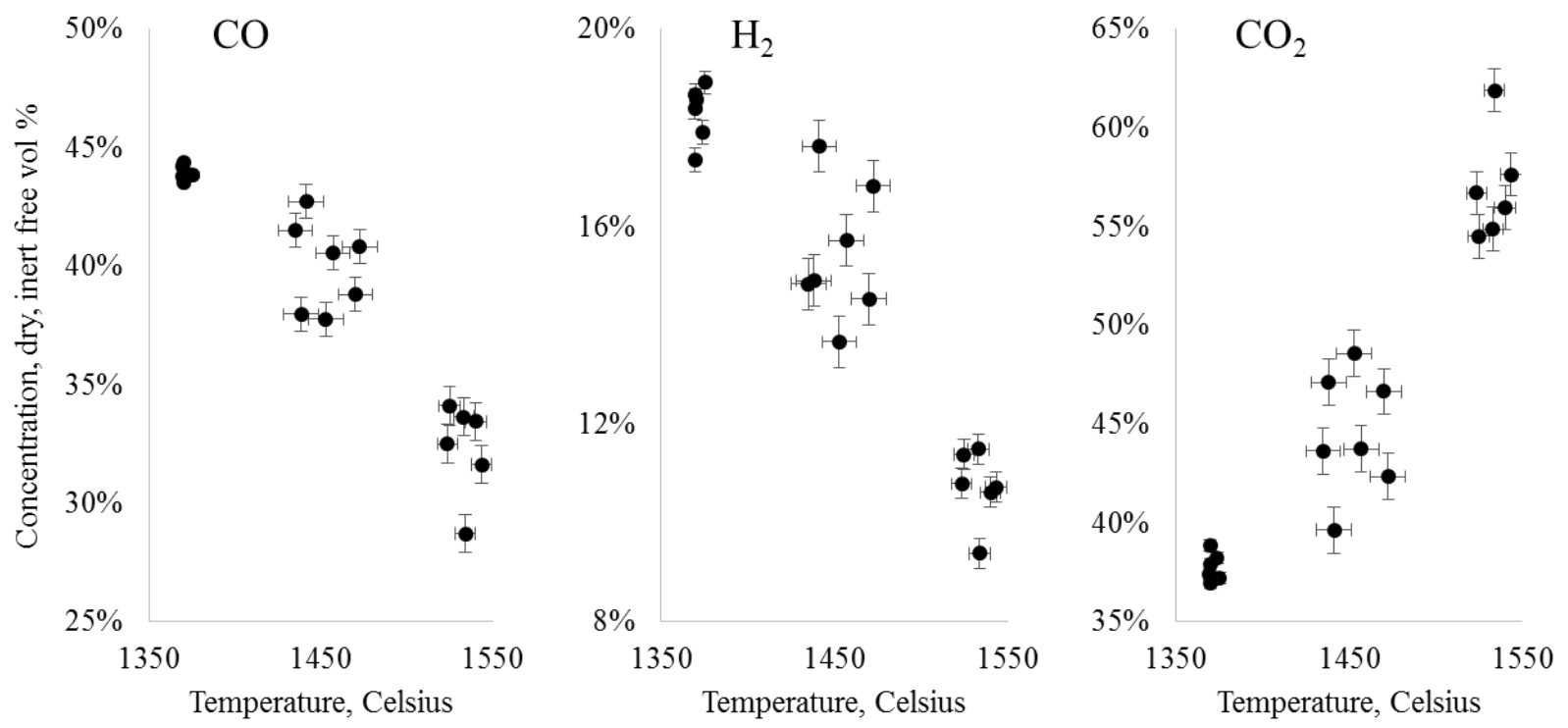

Figure 6: All measured gas concentrations for carbon monoxide (left), hydrogen (middle), and carbon dioxide (right), dry, inert free volume percent, versus temperature, ${ }^{\circ} \mathrm{C}$.

Distinct trends with temperature are evident in Figure 6 for all three species. Both carbon monoxide and hydrogen decrease with increased temperature as carbon dioxide increases due to decreased slurry flows and corresponding increase in $\mathrm{O}_{2} /$ fuel ratio. From a fluid mechanical perspective, the reduction in slurry flow shortens, or altogether moves, the flame region of the gasifier. The constant and minimal oxygen concentrations in the measured samples give confidence that flame did not move appreciably relative to the position of the sampling probe, and that the sampling position was well downstream of the flame.

Measured concentrations of syngas species versus radial position are presented in Figure 7. At each position, the average syngas composition is shown and error bars represent standard error based on multiple samples. The trends with temperature of Figure 6 are also evident in 
Figure 7, indicating that $\mathrm{H}_{2}$ and $\mathrm{CO}$ decrease while $\mathrm{CO}_{2}$ increases with temperature across all radial positions. This implies rapid gas-phase equilibrium due to turbulent mixing within and immediately following the flame region from where the probe extracted the gases.
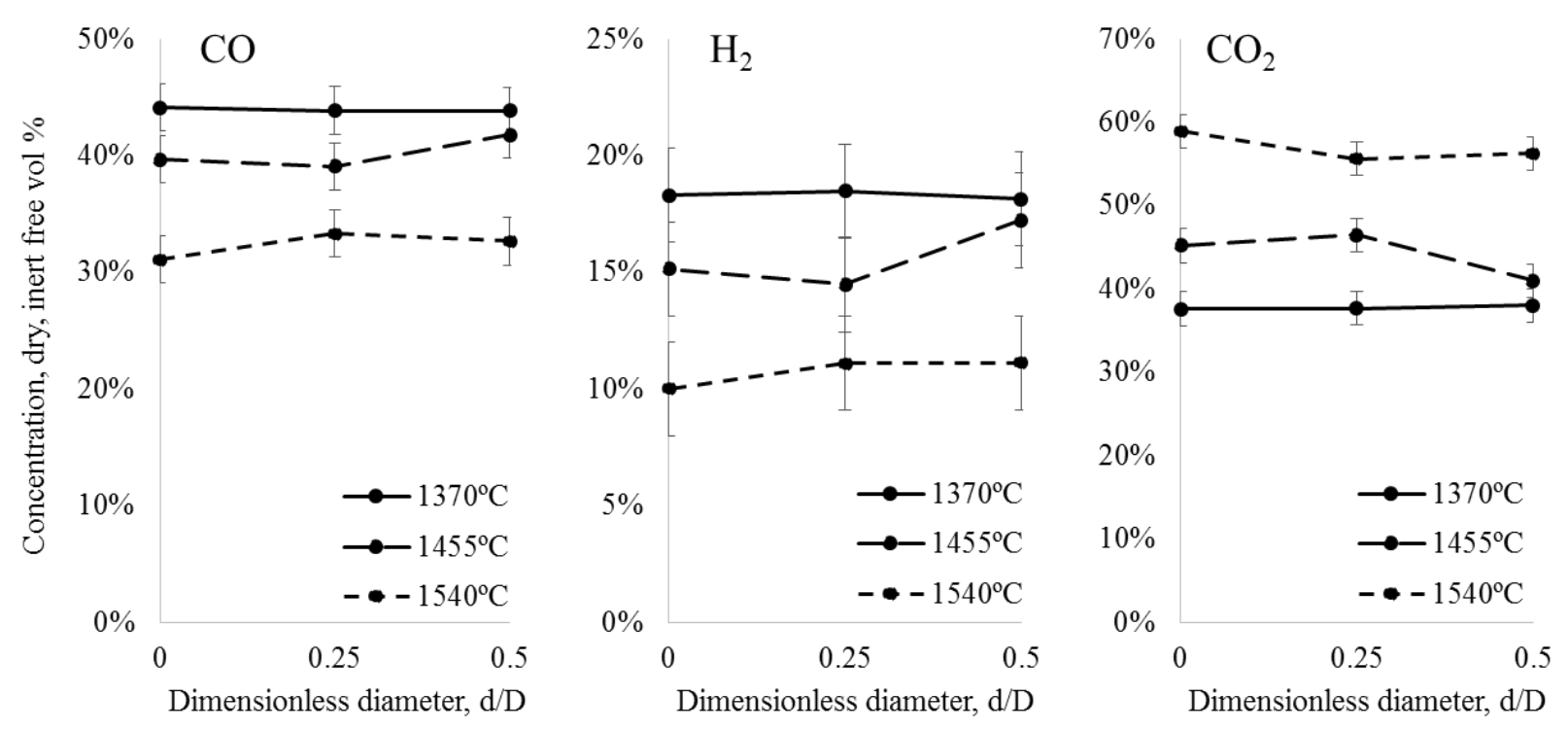

Figure 7: Average gas concentrations for carbon monoxide (left), hydrogen (middle), and carbon dioxide (right), dry, inert free volume percent, as a function of reaction zone diameter per setpoint temperature, $1370^{\circ} \mathrm{C}$ (solid), $1455^{\circ} \mathrm{C}$ (long dash), and $1540^{\circ} \mathrm{C}$ (short dash).

Figure 7 indicates no discernible trends in radial gas-phase composition. However, it is known that composition changes axially as char is gasified and gas-phase reactions take place. The sample port used in this study was in the heart of the reaction zone and it was expected that gasification was only partly complete at that position. Downstream of the sampling position, char continued to be converted through heterogeneous reactions primarily with steam and carbon dioxide, generating more syngas and changing its composition to a more energy-rich mixture. Finally, in the quench region the products are cooled by water sprays which add steam to the gas and may affect the final syngas composition. 
Figure 8 compares the average centerline gas concentrations at the reactor sampling position (pre-quench) with compositions measured post-quench after the gas had been cooled. Because the volumetric flow rate of gas changed between these positions as char was converted, the concentrations of carbon monoxide, hydrogen, and carbon dioxide were normalized against gas nitrogen concentrations. Nitrogen was only introduced to the gasifier as a purge gas in the burner region with a constant flow; therefore, it can be used as a tie component. Measured oxygen concentrations were below 0.5 volume percent in all samples for all temperatures, indicating that all oxygen fed through the injector was consumed in the flame region above the sampling point. Two key factors, heterogeneous gasification and the water-gas shift reaction, influence the change in gas concentration between the reaction zone and the reactor outlet (postquench). Downstream of the sample probe position, carbon in the char continued to react through heterogeneous gasification with steam $\left(\mathrm{H}_{2} \mathrm{O}+\mathrm{C} \rightarrow \mathrm{H}_{2}+\mathrm{CO}\right)$ and carbon dioxide $\left(\mathrm{CO}_{2}+\mathrm{C} \rightarrow 2\right.$ $\mathrm{CO})$.
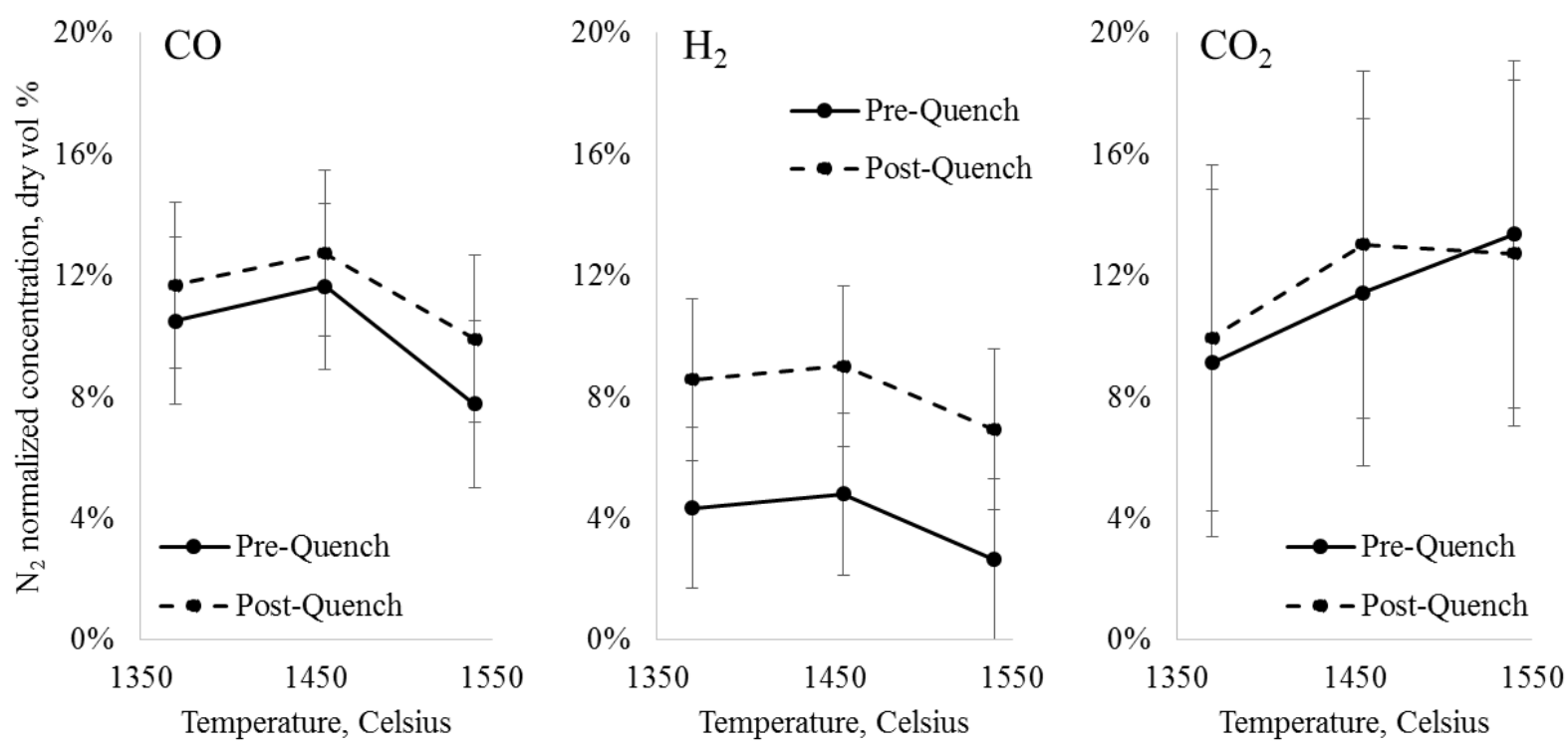

Figure 8: Gas concentrations for carbon monoxide (left), hydrogen (middle), and carbon dioxide (right), dry volume percent, as a function setpoint temperature for pre- and post-quench gas samples; pre-quench (solid) and post-quench (dash). 
Through the water-gas shift reaction $\left(\mathrm{H}_{2} \mathrm{O}+\mathrm{CO} \leftrightarrow \mathrm{H}_{2}+\mathrm{CO}_{2}\right)$, which occurs rapidly at these temperatures, steam in the syngas consumed $\mathrm{CO}$ produced through heterogeneous gasification to produce $\mathrm{CO}_{2}$ and $\mathrm{H}_{2}$. The hydrogen concentration at all three temperatures more than doubles as it progresses through the reactor, due to the combined influences of char gasification and the water-gas shift reaction. $\mathrm{CO}$ was slightly higher post-quench for all temperatures, suggesting significant production through the char gasification reactions. The concentration of $\mathrm{CO}_{2}$ increased post-quench for all but the highest temperature $\left(1540^{\circ} \mathrm{C}\right)$, for which it decreased slightly. This post-quench increase is attributed to the production of $\mathrm{CO}_{2}$ by the water-gas shift reaction and limited consumption of $\mathrm{CO}_{2}$ through heterogeneous gasification compared to steam gasification, which has been reported to occur 2-4 times faster than $\mathrm{CO}_{2}$ gasification [17-19]. It may be that the decrease in $\mathrm{CO}_{2}$ at the highest temperature is a consequence of more efficient $\mathrm{CO}_{2}$ gasification at that temperature.

The heating value of the syngas measured in the reaction zone differed from that at the gasifier outlet. Table 2 shows higher heating values (HHV) of the centerline gas and gasifier outlet gas calculated from measured syngas component concentrations. These calculations use the heats of formation under the assumptions that available hydrogen and carbon atoms are oxidized to form water vapor and carbons monoxide and dioxide, respectively. As one would expect, heating values decrease as the target temperatures increase. This is because the oxygento-fuel ratio increased to achieve higher temperature, resulting in higher production of carbon dioxide and less production of hydrogen and carbon monoxide, as observed in Figure 6 and Figure 7. 
Table 2: Calculated higher heating values $\left(\mathrm{kJ} / \mathrm{m}^{3}\right)$ of intermediate and outlet syngas compositions.

\begin{tabular}{l|c|c|c} 
Target Temperature $\left({ }^{\circ} \mathrm{C}\right)$ & $\mathbf{1 3 7 0}$ & $\mathbf{1 4 5 5}$ & $\mathbf{1 5 4 0}$ \\
\hline Centerline HHV $\left(\mathrm{MJ} / \mathrm{m}^{3}\right)$ & 7.3 & 7.0 & 5.1 \\
Product Syngas HHV $\left(\mathrm{MJ} / \mathrm{m}^{3}\right)$ & 7.7 & 7.3 & 6.7
\end{tabular}

\subsection{Sampling System Performance}

A motivation of this study was to make a sampling system as safe yet as simple as possible with few moving components. In the final design, the only moving part was the pneumatic cylinder used to position the tip of the sampling probe at different radial locations. The fastacting piston was able to position the probe tip within $8 \mathrm{~mm}$ of the target in under one second. The design of the pressure seal surpassed expectations. Mounting and properly aligning the flange assembly and probe extension to the gasifier sample port presented some challenges. A recommended change to the design is to use two seals with a small nitrogen purge between the seals, ensuring that the nitrogen pressure slightly exceeds that of the reactor. This will reduce the possibility of syngas exiting the seal assembly in case the seal leaks.

More corrosion-resistant materials of construction are also suggested. Although the probe was water-cooled, the tip was subjected to extreme conditions. Even when in the retracted position within the refractory wall of the gasifier, the probe extension was still subjected to high temperature and a corrosive atmosphere. When positioned at the wall or at the centerline of the reaction zone, the probe extension would be exposed to similar atmospheres, but temperatures in excess of $2200^{\circ} \mathrm{C}$. Use of more corrosion resistant high temperature alloys and possibly using a ceramic-tipped probe extension would be improvements, although one would want to design the tip to ensure that ceramic components were shielded and would not break if slag were to build up and solidify across the port while retracted. Metal tubing would still be necessary to guide the extension through the pressure seals and not cause the flange assembly to leak. 
Even though the probe extension is water cooled, some thermal deformation of the probe extension still occurred, as seen in Figure 9. The darkened metal surface was warped due to the high gasifier temperatures and by the longer sampling times at each of the three setpoints. During initial testing of the sampling probe, exposure time in the extended position was comparatively short. While collecting the samples in this study, the sample probe was kept in position for a longer period of time so that the sample container could be properly filled by the small flow of gas flowing through the critical orifice. This time difference may account for the deteriorated probe extension. The amount of time the probe is exposed to the reactor environment could be reduced by sampling a smaller volume of gas or using a larger critical orifice.

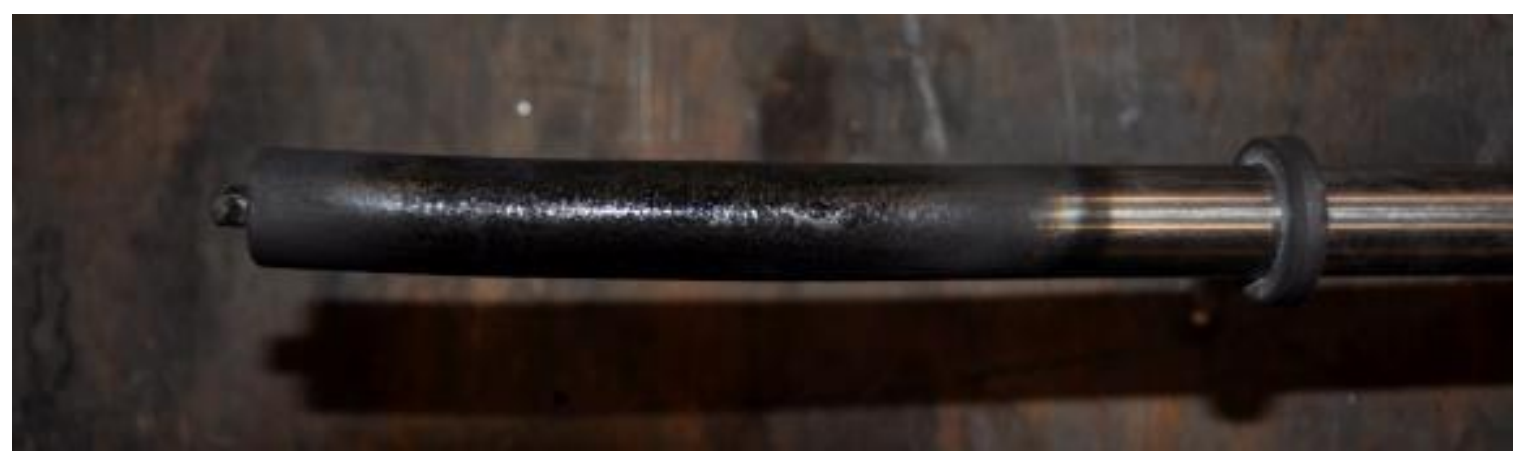

Figure 9: Top view of probe extension after completion of the sampling campaign. Deposits of char and slag are visible on the surface of the probe. The pressure seal, which is normally positioned farther to the right in the non-exposed region of the probe, can be seen in the photo.

Aside from some wear on the sampling probe, no problems with the sampling system were encountered. The control system monitored and controlled the system well, and positioning the probe with the pneumatic cylinder functioned better than expected. Recommendations for improved designs include a purged chamber between the pressure seals as mentioned previously, higher quality materials of construction, and minimization of time the probe spends in the 
reaction zone. Methods for leak detection are also advised as found in Carlsson et al. [2] and Wiinikka et al. [3], which include temperature and cooling water flow measurements.

\section{Conclusions}

A new extractive gas-phase sampling system that allows rapid radial positioning was designed, fabricated, and tested on a 1 ton/day pressurized entrained flow coal gasifier at 11 bar and at temperatures as high as $1540^{\circ} \mathrm{C}$. Particular care was taken to ensure safe operation of the water-cooled probe that could traverse the reaction zone, and the design proved successful over the range of conditions tested. Samples of gas within the reaction zone of the reactor were taken at three radial positions and gas compositions were analyzed by gas chromatography.

An experimental campaign to test the sampling system over a range of conditions and to examine the degree of radial variation in syngas composition was performed. As temperature increased from $1370^{\circ} \mathrm{C}$ to $1540^{\circ} \mathrm{C}$, carbon monoxide and hydrogen yields decreased as carbon dioxide increased, a result of an increase in oxidation associated with the higher $\mathrm{O}_{2} /$ fuel ratio needed at higher temperature. Syngas heating value decreased correspondingly. No discernible variation in gas composition with radial position was observed. Compared to the sampling location in the reaction zone of the gasifier, the gas concentrations measured at the outlet of the gasifier were richer in $\mathrm{H}_{2}$ and $\mathrm{CO}$, and generally lower in $\mathrm{CO}_{2}$. This is primarily a result of $\mathrm{H}_{2}$ and $\mathrm{CO}$ production by the heterogeneous steam and $\mathrm{CO}_{2}$ gasification downstream of the sampling location.

Although challenging to perform in the high pressure, high temperature environment of an entrained flow gasifier, the ability to sample the reactor environment at many radial and axial positions can greatly improve the understanding of this type of system. Combining gas phase 
measurements with compositional measurements of char collected in the quench will enable analysis of fuel conversion and production of gasification intermediates in future studies. This type of sampling also provides experimental data that can be used for validation of gasifier simulations. The pneumatically positionable sampling probe may also be useful for studying gas concentration profiles in other high pressure industrial processes such as ammonia synthesis and hydrocarbon cracking.

\section{Acknowledgments}

This material is based upon work supported by the U.S. Department of Energy under Award Number DE-NT0005015. The views and opinions of authors expressed herein do not necessarily state or reflect those of the United States Government or any agency thereof.

\section{References}

[1] U.S. Energy Information Administration, Total Energy, Annu. Energy Rev. (2013).

[2] P. Carlsson, H. Wiinikka, M. Marklund, C. Grönberg, E. Pettersson, M. Lidman, et al., Experimental investigation of an industrial scale black liquor gasifier. 1. The effect of reactor operation parameters on product gas composition, Fuel. 89 (2010) 4025-4034. doi:10.1016/j.fuel.2010.05.003.

[3] H. Wiinikka, P. Carlsson, F. Granberg, J. Löfström, M. Marklund, R. Tegman, et al., Design and methodology of a high temperature gas sampling system for pressurized black liquor gasification, Fuel. 89 (2010) 2583-2591. doi:10.1016/j.fuel.2010.02.021.

[4] S. Azuhata, P.O. Hedman, L.L.D. Smoot, W.A. Sowa, Effects of flame type and pressure on entrained coal gasification, Fuel. 65 (1986) 1511-1515. doi:10.1016/00162361(86)90326-1.

[5] N.R. Soelberg, L.D. Smoot, P.O. Hedman, Entrained flow gasification of coal 1. Evaluation of mixing and reaction processes, Fuel. 64 (1985) 776-781. doi:10.1016/00162361(85)90009-2. 
[6] B.W. Brown, L.D. Smoot, P.J. Smith, P.O. Hedman, Measurement and prediction of entrained-flow gasification processes, AIChE. 34 (1988) 465-446.

[7] J.R. Burklnshaw, L.D. Smoot, P. Hedman, A.U. Blackham, Analysis of Sulfur and Nitrogen Pollutants in Three-phase Coal Combustion Effluent Samples, Ind. Eng. Chem. Fundam. 22 (1983) 292-298.

[8] T.D. Prlce, L.D. Smoot, P. Hedman, T.D. Price, Measurement of Nitrogen and Sulfur Pollutants in an Entrained-Coal Gasifier, Society. (1983) 110-116.

[9] J.R. Highsmith, N.R. Soelberg, P.O. Hedman, L.D. Smoot, A.U. Blackham, Entrained flow gasification of coal 2. Fateof nitrogen and sulphur pollutants as assessed from local measurements, Fuel. 64 (1985) 782-788.

[10] K.M. Nichols, P.O. Hedman, L.D. Smoot, Release and reaction of fuel-nitrogen in a highpressure entrained-flow gasifier, Fuel. 66 (1987) 1257-1263.

[11] H. Kobayashi, J.B. Howard, A.F. Sarofim, Coal devolatilization at high temperatures, Symp. Combust. 16 (1977) 411-425.

[12] D.J. Harris, D.G. Roberts, D.G. Henderson, Gasification behaviour of Australian coals at high temperature and pressure, Fuel. 85 (2006) 134-142.

[13] A. Tremel, T. Haselsteiner, M. Nakonz, H. Spliethoff, Coal and char properties in high temperature entrained flow gasification, Energy. 45 (2012) 176-182. doi:10.1016/j.energy.2012.02.028.

[14] A. Tremel, H. Spliethoff, Gasification kinetics during entrained flow gasification - Part II: Intrinsic char reaction rate and surface area development, Fuel. 107 (2013) 653-661.

[15] A. Tremel, H. Spliethoff, Gasification kinetics during entrained flow gasification - Part III: Modelling and optimisation of entrained flow gasifiers, Fuel. 107 (2013) 170-182.

[16] D.R. Wagner, Coal Conversion Experimental Methods for Validation of Pressurized Entrained-Flow Gasifier Simulation, Doctoral Dissertation, University of Utah, 2013.

[17] D.G. Roberts, D.J. Harris, Char Gasification with O 2 , CO 2 , and H 2 O: Effects of Pressure on Intrinsic Reaction Kinetics, Energy \& Fuels. 14 (2000) 483-489. doi:10.1021/ef9901894.

[18] H.-J. Mühlen, K.H. van Heek, H. Jüntgen, Kinetic studies of steam gasification of char in the presence of H2, CO2, and CO, Fuel. 64 (1985) 944-9.

[19] D.P. Ye, J.B. Agnew, D.K. Zhang, Gasification of a South Australian low-rank coal with carbon dioxide and steam: kinetics and reactivity studies, Fuel. 77 (1998) 1209-1219. 